38 Garner DM, Bemis KM. A cognitive-behavioral approach to anorexia nervosa. Cognitive Therapy and Research 1982;6:123-50.

39 Garner DM, Bemis KM. A cognitive-behavioral approach to anorexia nervosa. In: Garner DM Garfinkel PE, eds. Handbook of psvchotherapy for anorexia nervosu and bulimia. New York: Guilford, 1985:107-46.
40 Cooper Z, Fairburn CG. The eating disorder examination: a semi-structured interview for the assessment of the specific psychopathology of eating disorders. International foumal of Eating Disorders 1987;6:1-8.

41 Cooper Z, Cooper PJ, Fairburn CG. The validity of the eating disorder examination and its subscales. Br f Psychiatry 1989;154:807-12.

\title{
Community care
}

\section{Research studies are essential}

Over the next decade the organisation and delivery of health care in the community will present the National Health Service with one of its most demanding tasks. If it is to succeed then studies and demonstration projects will need to be organised and carried out in all parts of the country.

The 1990s will see growing demands for comprehensive care and support of elderly, mentally ill, mentally handicapped, and physically disabled people either in their own homes or in residential accommodation in the community. A change is unavoidable-partly because of the increasing numbers of very elderly people ${ }^{1}$ and partly because of the fall in the number of school leavers, from whom the NHS recruits most of its staff. ${ }^{2}$ Only within the community are to be found the involuntary and voluntary carers and helpers needed to supplement scarce statutory services.

In November last year, the government published its long awaited proposals for community care. ${ }^{3}$ The white paper contained welcome emphasis on enabling people to live in their own homes, support for carers, proper assessment of need and good case management; and a real attempt to abolish current confusion and to clarify the responsibilities of agencies. Certainly it will help to remove several uncertainties and allow planning to proceed. No one, however, should minimise the task facing those authorities in making effective arrangements for delivering the services. ${ }^{+}$

There will still be an enormous array of agencies and staff with separate responsibilities and different loyalties. These include local social services, housing, and education; health authorities; family practitioner committees; general practitioners, both budget and non-budget holding; and nurses working for health authorities, general practitioners, hospitals providing outreach services, voluntary services, and residential and nursing homes. They will have to collaborate to ensure the best use of resources and the effective delivery of suitably integrated services.

Those in need of care also have to be identified. Their problems and capabilities must be assessed and progress predicted; and the frail elderly, those with chronic degenerative disorders, and many others will need regular reassessment. Welding together the various agencies and disciplines to reach joint decisions and to collaborate in exercising their responsibilities will require managerial skill and diplomacy. And this will be against local backgrounds of immense diversity in terms of geography, demography, and the ways in which services have been organised and developed.

Health and local authorities face two main tasks. Firstly, they will need to establish new management structures and mechanisms for coordinating the work of the agencies providing (or purchasing) and delivering services. These will need to be monitored, evaluated, amended, and developed. This will be achieved only with the help of research, underpinned by information systems. A recent innovative study in Newcastle upon Tyne examined the provision of care for physically handicapped and frail elderly people in the community, identifying the various relations between agencies and staff. ${ }^{6}$ The study team concluded that even in a city with excellent and well coordinated services the problems were sufficiently complex that responsibility should be devolved to a new, free standing, publicly accountable consortium formed by the health authority and the city council. Such a scheme might be regarded as at one end of a spectrum of options open to authorities in the light of the white papers on the health service ${ }^{7}$ and on community care. ${ }^{3}$ Another different and simpler approach adopted by some district health authorities in trying to unify services has been to introduce "advocates," whose role is to secure services and coordinate their delivery directly on behalf of individual clients. $^{8}$

The second main requirement is to develop outcome measures in community care, which at present are seriously deficient; among these must be assessment of the quality of life and patient satisfaction. Only in this way can the effectiveness of services be assessed.

If we are to achieve soundly based developments in community care - bearing in mind the wide local diversities the prime requirement is for district health authorities and local social service authorities to conduct studies and experiments. Such studies must flourish independently of priorities determined regionally or centrally. The authorities must be encouraged and helped, and in particular they must allocate or obtain sufficient finances to fund research. Such studies may be undertaken by their own staff, by academic departments, or by management consultants. There will be problems (in care and service delivery, for example) that are better examined on a multidistrict or regional basis, so a regional research capability will still be needed. And there will be problems with multiregional or national dimensions. Because government departments must respond to the requirements of ministers, the final tier needed may be an independent authority on the lines recommended by the Lords Select Committee ${ }^{9}$ or an institute of health as recommended by Sir Kenneth Stowe. ${ }^{10}$ Though the government's response to the former is less than encouraging. ${ }^{11}$

We should, then, expect to see a growth of monitoring of developments, exchange of information, and dissemination of good practice. But the most urgent need is to ensure that the authorities directly concerned with the development and delivery of local services can command studies and research into their own locally defined problems. This poses a particular challenge for public health doctors. A second pressing need is a much closer relation between the health service, academic departments, and funding agencies to develop research methods and measures and to train researchers.

Secretary,

Nuffield Provincial Hospitals Trust,

London NW1 7SP 
1 Office of Population Censuses and Survevs. Population projections, 1981-2021. London: HMSO, 1983.

2 Livesley B. Running out of staff for the NHS. Br Med f 1989;299:1-2.

Secretaries of State for Health, Social Security, Wales and Scotland. Caring for people. London: HMSO, 1989. (Cmnd 849.)

Blaxter M. The meaning of disability. London: Heinemann, 1976.

Maclean U. Dependent territories. London: Nuffield Provincial Hospitals Trust, 1989.

6 Banham BJ, Luckman J. Community care: partnership in action. London: Business Sciences (UK),

1989.
7 Secretaries of State for Health, Wales, Northern Ireland, and Scotland. Working for patients. London: HMSO, 1989. (Cmnd 555 .)

8 Dant T, Carley M, Gearing B, Johnson M. Co-ordinating care. Milton Keynes: Open University, 1989

9 Lords Select Committee on Science and Technology on Priorities in Medical Research. Report. London: HMSO, 1988. (3rd report, 1987-88, HL 54.)

10 Stowe K. On caring for the National Health Service. London: Nuffield Provincial Hospitals Trust, 1989.

11 Department of Health. Priorities in medical research. London: HMSO, 1989. (Cmnd 902.)

\section{Clinical directorates}

\section{Consultants' clinical independence needs to be preserved}

In 1984 in response to a severe financial crisis Guy's Hospital decided to adopt the Johns Hopkins model of management and in so doing pioneered resource management in Britain. The medical staff, together with the nurses, took over the responsibility for managing the hospital. One of the key features of the Guy's management structure is that the running of the hospital is vested in a hospital management board, whose chairman is a consultant. In addition there are 16 clinical directorates, each headed by a lead clinician, who is a member of the board. Each director holds a budget, and to him or her is delegated responsibility for a wide range of activities including waiting lists and outpatient management. ${ }^{1}$

In the past year or two considerable pressure has been brought on all consultants to imitate this system of clinical directorates as a necessary step on the road to resource management - though the value of such management remains unproved. ${ }^{2}$ In many cases the imitations have been a pale shadow of the Guy's experience. Boards of directors have evolved into groups of "lead clinicians" who are responsible to management for carrying out health authority policy - a far cry from the Guy's ideal of a group of doctors accepting corporate responsibility for the running of the hospital. The term "director" itself carries a certain status-"one who directs," or "a member of a governing body." But the term also carries the implication that the director himself is responsible to someone higher up the ladder. It places the consultant very firmly in a chain of management - with the implication that other, non-directorial consultants are tacitly drawn into the managerial chain at a lower level. Lay managers probably see the system as a means of exerting control over the hitherto unassailable autonomy of consultant decision making. Is that what the Guy's pioneers had in mind?

The consequences of abandoning consultant independence for a place in line management have very practical aspects. Where, for example, does a director stand in circumstances of severe underfunding? Lay managers will say that a director's duty is to agree a budget and to tailor his or her workload to match. But if a budget is inadequate a doctor's natural instinct may be to continue to treat as many patients as possible-and allow the money to run out, thus drawing attention to the underfunding. Such medical pressure has undoubtedly contributed to causing the government to make large injections of funds into the NHS in recent years. Are consultants now to be muzzled? A clinical director must walk a fine tightrope to be able to retain the right of independent criticism on the one hand but agree to work within a budget on the other. It is scarcely conceivable that industry would allow its middle and upper levels of management such unrestrained liberty.

The problems inherent in clinical directorates are not confined to the profession's relations with lay management, and many of these are discussed in the report published last week by the Institute of Health Service Management (p 492). ${ }^{3}$ Interaction between the director and his or her fellow consultants is likely to prove troublesome. Anecdotes already abound of clinical directors who regard their title as giving them authority to influence their colleagues' clinical decisions -how else can they be responsible for their budgets? Fortunately, on this at least, the institute's report has given unequivocal guidance by emphasising that "the lead consultant does NOT . become the manager of his or her consultant colleagues - the essence of clinical freedom of the individual practitioner remains intact."

How should doctors react when clinical directorates are proposed? The first questions that every consultant should ask are: "Precisely what is going to be different from the present system? What constraints are going to be applied (by lay managers or clinical colleagues) which will affect my clinical practice or way of working? Only when these questions are answered fully can a decision be taken. In many instances consultants are badly informed about what awaits them. They are fobbed off with the suggestion that directors will be, in effect, the same as chairmen of cogwheel divisions, with the management board becoming a type of medical executive committee: in other words, nothing will really change. Such an explanation should always raise the deepest suspicions. Why would managers go to such lengths (including that of paying the directors) in order to preserve the existing system?

The choice of director must always be acceptable to clinical colleagues and that person must be someone with whom management can work. This can be ensured by clinicians nominating suitable people for management to approve. To appoint a director who did not have the confidence of his or her consultant colleagues would be a recipe for disaster. A realistic assessment must be made of the work required, with arrangements for appropriate and acceptable remuneration and reduction in clinical workload during a consultant's term as director.

These are but a sample of the issues facing consultants who are being urged to form directorates. Professional bodies need to issue clear, concise, and comprehensive guidance to doctors if inappropriate and undesirable management systems are to be avoided and the clinical independence of consultants maintained.

Consultant Surgeon,

J N JOHNSON

Halton General Hospital,

Runcorn,

Cheshire WA7 2DA

I Buxton M, Packwood T, Keen J. Resource management process and progress. London: Health

Economic Research Group, 1989.
2 Central Consultants and Specialists Committee of the British Medical Association. Resource management initiative: an evaluation of the six experimental sites. London: BMA, 1989.

Disken S, Dixon M, Halpern S, Schocket G. Models of clinical management. London: Institute of Health Services Management, 1990. 